\title{
Configurações
}

Revista de sociologia

\section{O difícil percurso da lusofonia pelos trilhos da 'portugalidade'}

The difficult journey of lusophony along the paths of 'Portugality'

Le parcours diffi cile de la lusophonie sur les chemins de la " portugalité »

\section{Vítor de Sousa}

\section{OpenEdition}

\section{Journals}

\section{Edição electrónica}

URL: http://journals.openedition.org/configuracoes/2027

DOI: $10.4000 /$ configuracoes.2027

ISSN: $2182-7419$

\section{Editora}

Centro de Investigação em Ciências Sociais

\section{Edição impressa}

Data de publição: 1 Dezembro 2013

Paginação: 89-104

ISBN: 1646-5075

ISSN: 1646-5075

\section{Refêrencia eletrónica}

Vítor de Sousa, "O difícil percurso da lusofonia pelos trilhos da 'portugalidade' », Configurações [Online], 12 | 2013, posto online no dia 23 outubro 2014, consultado o 30 abril 2019. URL : http:// journals.openedition.org/configuracoes/2027; DOI : 10.4000/configuracoes.2027

Este documento foi criado de forma automática no dia 30 Abril 2019.

(c) CICS 


\title{
O difícil percurso da lusofonia pelos trilhos da 'portugalidade'
}

\author{
The difficult journey of lusophony along the paths of 'Portugality' \\ Le parcours diffi cile de la lusophonie sur les chemins de la "portugalité »
}

\section{Vítor de Sousa}

\section{Introdução}

1 Falar de lusofonia ${ }^{1}$ implica abrir o significado da palavra, levando-o para além do seu sentido estrito. Trata-se, no entanto, de um exercício que denota, desde logo, uma incapacidade: a de sintetizar numa palavra apenas uma ideia que aglutine um pensamento e o represente - o que pode ser visto também como uma polissemia interpretativa que lhe confere outro lastro, enriquecendo-a. O certo é que o sentido de 'lusofonia' fi caria amputado se correspondesse, apenas, aos falantes de português espalhados pelo mundo e não consubstanciasse um lugar simbólico e cultural, extravasando a correspondência semântica de proximidade que lhe esteve na origem, num mundo cada vez mais globalizado, que se inscreve no presente (Martins, 2006a).

2 A consideração desta variável na problemática da lusofonia faz toda a diferença nas possíveis produções de sentido da palavra, cuja utilização foi disseminada após a queda do 'império colonial português', tendo, por conseguinte, um recorte pós-colonial. No trauma decorrente da relação unidirecional de poder entre colonizadores e colonizados, subjazem laços culturais e uma língua comum, embora falada de forma diferente consoante as coordenadas geográficas. Trata-se de uma constatação que se reporta à etimologia da palavra com a referência-base a remeter para 'luso' (português), que decorre de 'lusitanidade' e pode invocar uma 'portugalidade' encapotada, termo que serviu de bandeira ao Estado Novo português, mormente a partir das décadas de 50 e 60 do século XX, através da ideia de "Portugal do Minho a Timor". 
Quase quatro décadas após a descolonização, as tensões entre ex-colonizadores e excolonizados ainda se fazem sentir, evidenciando que o processo de colonização foi violento e deixou marcas, contrariando a retórica oficial da propaganda do Estado Novo.

\section{A construção da lusofonia}

4 A ambiguidade do conceito de 'lusofonia' faz com que ele se afigure problemático logo a partir do seu espaço-âncora, a Comunidade dos Países de Língua Oficial Portuguesa (CPLP). A atestá-lo está o facto de a palavra ter ficado de fora da Declaração Constitutiva da instituição ${ }^{2}$, não obstante a sua utilização ser pós-colonial; para além disso o termo 'lusofonia', a par de 'lusófono', existe desde 1950 e o seu significado está estabelecido nos dicionários de referência da Língua Portuguesa, como são os casos do Dicionário da Academia das Ciências de Lisboa (2001) e do Dicionário Houaiss da Língua Portuguesa (2003 [2011]). Regina Brito e Neusa Bastos lembram, porém, que a palavra 'lusofonia' remete para Lusitânia, província romana dominada pela Hispânia, povoada pelos lusitanos, enquanto o termo 'luso' (do latim 'lusu') remete para lusitano, ou seja: significa português ou referente a Portugal (Brito \& Bastos, 2006: 65), o que provoca, não raras vezes, um certo desconforto no seio dos outros países daquela estrutura (Mata, 2013: 141).

Carmen Maciel observa que, até 1999, "a lusofonia era definida apenas como a adoção da língua portuguesa como língua de cultura, franca ou oficial" (Maciel, 2010: 83), lembrando que para esse estado de coisas contribuiu a criação da CPLP. A autora defende que "as noções de 'coletividade' e 'comunidade' começam a estar integradas nas definições avançadas nos dicionários, tanto brasileiros como portugueses", pelo que que a lusofonia passa de "fenómeno linguístico" a "fenómeno social" (ibid.). Trata-se de uma observação já antes feita por Eduardo Lourenço, que salienta que a lusofonia extravasa uma ideia limitada de espaço linguístico, que já tem subjacente "a genealogia que a distingue entre outras línguas românicas e a memória cultural que, consciente ou inconscientemente, a ela se vincula" (Lourenço, 2004: 174). O autor adverte, também, que o conceito aparentemente inocente de lusofonia pode arrastar consigo "as mesmas imagens, o mesmo cortejo de fantasmas, os mesmos subentendidos e mal-entendidos, nos diversos espaços que atribuímos, sem uma onça de perplexidade, à ideal e idealizada esfera lusófona" (ibid:: 174-175). Talvez por isso Moisés de Lemos Martins, Helena Sousa e Rosa Cabecinhas se refiram à lusofonia como "uma construção extraordinariamente complexa", desenvolvida num espaço geolinguístico "altamente fragmentado", através de um sentimento "pleno de contradições", que decorre de uma memória assente num passado comum "para o bem e para o mal". Para estes autores, a lusofonia, para além de património simbólico, "em permanente disputa", integra ainda instituições "cujos objetivos políticos são também eles próprios difusos e - não raramente - conflituosos" (Martins, Sousa \& Cabecinhas, 2007: 309). No entanto, perante a crescente globalização, existe uma oportunidade tendente a uma melhor compreensão do 'Espaço Lusófono', que poderá contribuir para o desenvolvimento de outro tipo de perspetivas, que reputam de alternativas, "e necessariamente mais complexas", em que uma língua comum "poderá mudar a forma como a 'diferença' é percebida" (ibid.).

6 O certo é que o fantasma do 'império colonial português' parece continuar a pairar quando se aborda a problemática da lusofonia. Hoje, no entanto, essa evidência é menos intensa do que no período pós-revolução de 1974, embora os resquícios subjazam quando estão envolvidos Portugal e os restantes países da denominada CPLP. As tensões entre as 
partes vêm, periodicamente, ao de cima, sendo refletidas nos média de cada país, que aproveitam as mais diversas temáticas como pretexto para sublinhá-lo. Não obstante, Moisés de Lemos Martins dá outra dimensão ao conceito de lusofonia, extravasando de uma perspetiva meramente ideológica e defendendo que ele vai para além de "objecto de mera curiosidade histórico-linguística ou até histórico-cultural", pelo que se assume, hoje, como um tema que congrega interesses "que têm a ver não apenas com aquilo que os países lusófonos são como língua e cultura no passado, mas também, sobretudo, com o presente e com o destino do 'continente imaterial' que estes países constituem" (Martins, 2006a: 17). Em direção contrária segue Michel Cahen, que defende que a cultura lusófona não existe, nem existem culturas que possam ser assim classificadas, mesmo que a sua expressão seja feita em português, facto que "não as fa[z] 'irmãs', ou gémeas, por utilizarem a mesma língua" (Cahen, 2013: 297).

José Carlos Venâncio, de forma mais aberta, observa que a lusofonia traduz "a condição dos que se exprimem na língua portuguesa: tenham-na como língua materna, oficial ou de património" (Venâncio, 2013: 85), condicionando, desse modo, "mesmo para os que não o tenham como língua materna, a vivência cultural dos falantes, de forma a que parte da sua identidade se espelhe precisamente no uso que fazem da língua" (ibid.). Nesse sentido, e porque se trata de um processo que não é estático, alicerçado "em campos comunicacionais assistidos por dinâmicas grupais", o autor diz entender que seria mais apropriado "falar-se de Lusofonias, em vez de Lusofonia" (ibid.).

Na opinião de Maria Manuel Baptista, "a lusofonia sinaliza e encobre em Portugal o lugar verdadeiramente 'não dito', uma espécie de espaço fantasmático da nossa cultura, apesar de paradoxalmente tanto se utilizar este conceito" (Baptista, 2006: 24); deste modo, a autora entende que se verifica do lado português uma estratégia de "esquecimento ativo", em relação à história coletiva que liga Portugal e os ex-países colonizados. Há, por isso, muito caminho a percorrer para que exista uma verdadeira comunidade lusófona, sendo necessário que sejam ultrapassados "os interesses pontuais de pequenos grupos políticos, económicos e de parte das elites intelectuais dos respectivos países”, o que passa pela "tomada de consciência da diversidade histórica, cultural, simbólica e imaginária dos diversos povos falantes do português", sem cair, no entanto, "no domínio do relativismo ético e cultural, onde afinal tudo se equivale e nenhum projecto vale verdadeiramente a pena ser sonhado e muito menos concretizado" (Baptista, 2000: $\mathrm{s} / \mathrm{p}$ ).

Miguel Real refere que já quase tudo foi dito sobre a lusofonia, faltando apenas fazê-la (2012), ideia com a qual concorda Jessica Falconi que evidencia que a vasta bibliografi a existente sobre a questão da lusofonia "mostra que se trata de um terreno controverso" e uma questão de difícil resolução (Falconi, 2013: 279).

\section{A ideia de 'Império' e o caso português}

Thomas Richards (1993) refere-se à noção de 'império' como se se tratasse de uma nação em excesso, ideia que poderá estar na base da observação de Edward Said sobre o fim do colonialismo, o qual contudo continua a persistir no plano cultural, repercutindo-se nas práticas políticas, ideológicas, económicas e sociais (Said, 1994). Por seu turno, Michel Cahen constata que vários conceitos coloniais, como 'lusitanidade' ['portugalidade'] e 'império', "sobreviveram perfeitamente à descolonização", uma vez que "o que foi condenado com o salazarismo foi bem mais o seu colonialismo, como política, do que a colonização como obra"; por esse motivo a lusofonia é um conceito eminentemente 
político e ideológico (Cahen, 2013: 298). O imaginário português foi, assim, apenas parcialmente descolonizado, e o conceito de lusofonia "apaga numa única palavra realidades sociais extremamente diferentes e status sociais incomparáveis" (ibid.: 303).

11 A propósito do império colonial português, Leonor Pires Martins observa que a ideia de nação se deslocou para um imenso aglomerado de territórios "dispersos e distantes entre si, cujo domínio direto e efetivo acabaria por ser mais fictício do que real, mais da ordem do ilusório do que do factual" (Martins, 2012: 20). E, muito embora o mapa desenhado no tempo dos colonialismos já não sirva, Jessica Falconi observa que a duração das antigas fronteiras "foi interiorizada pelos projectos das nações independentes, aliada à reprodução e ao surgimento de antigos e novos vectores de desigualdade, que (re)fragmentam a 'unidade' do mundo" (Falconi, 2013: 277), o que constitui uma "herança" problemática que continua a pairar no plano simbólico.

Uma pista para esse estado de coisas pode ser dada pelo modus operandi do Estado Novo, exponenciando e inventando alguns 'mitos de origem' do país, numa lógica assente na propaganda do regime. Fernando Rosas (2001) destaca que um dos mitos ideológicos fundadores do Estado Novo foi o "mito imperial", no seu duplo aspeto de colonizar e evangelizar, numa ideia que é complementada por Luís Reis Torgal, ao reputar o multirracialismo como o "grande mito da política colonial ou ultramarina portuguesa" (Torgal, 2009: 493). Esta ideia, como nota Boaventura de Sousa Santos, fez com que o 'império' enfatizasse uma cultura alegadamente 'superior', já que resultava de uma imposição aos outros, os 'gentios' (Santos, 1999).

13 Leonor Pires Martins assinala que os vários domínios ultramarinos só foram apreendidos pelos portugueses através da promulgação de legislação específica (de que é exemplo a publicação, em 1930, do "Ato Colonial"), da propaganda do regime, bem como da difusão de imagens mostrando o "Portugal do Minho a Timor" em toda a sua extensão geográfica. Deste modo, como refere Margarida Ribeiro Sanches, foi-se consagrando o estado-nação imperial como um todo coerente, não obstante "as visões distintas, as idiossincrasias, as contradições e os limites das 'missões civilizadoras', baseadas em querelas nacionais", também elas fundadoras do moderno estado-nação (Sanches, 2012: 195). Para além disso, os discursos em torno do império sempre estiveram amputados de uma lógica de igualdade entre colonizadores e colonizados, decorrentes de uma alegada inferioridade civilizacional dos últimos em relação aos primeiros. Foi exatamente dessa forma que os modernos estados-nação imperiais, como foi o caso português, fundamentaram "a sua 'missão histórica' em África”, com cada colónia a ser como que o prolongamento da nacionalidade (Sanches, 2012: 196). A historiadora refere-se ao modo como as teorias surgidas e defendidas em determinados lugares sofrem processos de transformação, não só em virtude do tempo em que são cunhadas, mas principalmente através dos lugares em que são lidas, "dando assim lugar ao que se designa por processos [...] de apropriação criativa" (idem, 2011: 9). Essa correspondência poderá estender-se à perspetiva "póscolonial", termo que se naturalizou no vocabulário nacional e que permite, pelo menos em Portugal, "uma revisitação mais ou menos pacificada de um passado que se deseja definitivamente morto e enterrado" (ibid.: 9-10), muito embora subjazam alguns equívocos. Para o efeito, como sublinha Maria Paula Meneses, muito têm contribuído as novas perspetivas epistemológicas, cujo trabalho tem incidido em "descentrar o olhar e as conceções eurocêntricas na análise social, introduzindo uma análise crítica para transformar o presente, onde a análise das estratégias discursivas desempenha um papel fundamental" (Meneses, 2013: 320). 


\section{A construção da 'portugalidade'} língua portuguesa e os dicionários mais comuns, como é o caso do que é editado pela Porto Editora, o traduzam como "qualidade do que é português" ou "sentido verdadeiramente nacional da cultura portuguesa" (Costa \& Melo, 1995), a sua cunhagem é balizada pelo portal Ciberdúvidas da Língua Portuguesa nas décadas de 50 e 60 do século $\mathrm{XX}^{3}$, portanto, em pleno Estado Novo ${ }^{4}$. Trata-se de um conceito, desde logo, centrado no 'eu' (Portugal) e que pode ser contextualizado na ideia de "Portugal do Minho a Timor". 0 slogan do Estado Novo começou em 1951 com a revogação do "Ato Colonial”, com o qual o Governo português passou a defender que Portugal seria um todo uno e indivisível, do Minho a Timor, em que todas as colónias passariam a ser províncias, tal como as outras que existiam na metrópole. Foi desenvolvida, a partir daí, uma retórica destinada a sustentar um mito que apoiasse a ideia de que não haveria razões para o desenvolvimento de movimentos independentistas nos territórios portugueses de África e da Ásia. De resto, a 'portugalidade' entra no discurso político apenas a 27 de abril de 1951 - dezasseis anos após o início da Assembleia Nacional (AN) -, servindo esta, através do único partido existente (a União Nacional), de eco da governação, disseminando a ideologia do Estado Novo (Sousa, 2013). como estando no domínio da política. Trata-se de uma classificação social, com uma série de aspetos práticos associados. No pós-25 de Abril a utilização da palavra 'portugalidade' foi utilizada de forma residual, na sequência de um corte ideológico com o passado.

Hoje, fala-se com algum à-vontade sobre o assunto, não obstante este dever ser contextualizado, uma vez que a 'portugalidade' está, como vimos, datada. Mesmo que Wittgenstein tenha referido que o sentido que se dá às palavras seja o seu uso ${ }^{5}$, torna-se necessária essa contextualização, até para evitar eventuais equívocos, uma vez que a 'portugalidade' remete para um regime simbólico centrado em Portugal.

Eduardo Lourenço (1954) sustenta que a existência mítica precede a existência empírica e que "toda a leitura do nosso passado [...] está suspensa [das] Descobertas" (idem, 2005: 35). Por seu turno, José Eduardo Franco refere-se a Portugal como estando associado a um mito, com o país a ser "visto como um reino eleito para uma missão especial, de carácter sagrado, no panorama planetário". Nesse sentido, refere que "é a partir da poesia e da historiografia que são cantadas e 'memorizadas' as gestas [das Descobertas], [...] nas quais se reforçam as bases míticas da portugalidade" (Franco, s/d: 69).

18 A respeito do mito, Roland Barthes fala na sua ação tendente a converter a história em natureza e o contingente em eternidade, sendo que o mundo fornece ao mito "um real histórico, definido, por mais longe que se recue no tempo, pela maneira como os homens o produziram ou utilizaram; e o que o mito restitui é uma imagem natural desse real" (Barthes, 1978 [1957]: 209).

19 Esta ideia leva-nos ao "discurso da identidade" (Martins, 1996), em que, segundo Albertino Gonçalves, se destacam três efeitos: de reificação, de desdialetização e de dominação (Gonçalves, 2009: 61). Estes efeitos remetem assim, para essências, estando estas ligadas a estados (lusitanidade [portugalidade]) ou a destinos (Quinto Império), que "absolutizam o que é relativo, substantivam o que é relacional, fundamentam na natureza 
ou no mito o que é histórico" (ibid.). A essencialização do real propicia, nesse sentido, efeitos de reificação (ibid.). Esta circunstância evidencia que, "uma vez (pre)dita, à entidade resta-lhe cumprir a predição" (ibid.). Por essa razão, justifica-se, neste contexto, a convocação do Princípio de W. I. Thomas relativo às predições criadoras: "uma crença falsa nos seus fundamentos pode revelar-se verdadeira nas suas consequências" (ibid.: 62); "Os discursos de identidade tendem a suspender ou a exorcizar a negatividade", e "tanto a hetero-identificação, que categoriza o outro, como a autoidentificação, que reconhece o semelhante, diluem e atropelam a diversidade" (ibid.); "Socialmente construídas, as identidades, sempre polémicas, envolvem bricolages ideológicos" (ibid.: 63). Consoante os casos e as circunstâncias, estas construções podem ser mais ou menos bem-sucedidas; "Convém, contudo, não esquecer que relevam de estratégias de poder que, operando com arbitrários culturais, implicam o recurso à violência simbólica" (ibid.); "Relativas e questionáveis, as propostas identitárias tendem a converter-se, pela fé e pela crença, em princípios absolutos (ibid.).

Reencontramos, mais uma vez, a alquimia da dominação e o efeito de reificação. 0 meio ultrapassa o fi m e a essência trava a potência" (ibid:: 63). Ora, como refere Denys Cuche, não existe uma "identidade cultural em si, definível de uma vez por todas". Por essa razão, "a análise científica deve renunciar a pretender descobrir a verdadeira definição das identidades particulares que estuda", sendo que a questão não é sabermos, por exemplo, "o que são 'verdadeiramente' os corsos, mas o que significa o recurso à identificação 'corso"' (Cuche, 2006 [1999]: 153).

21 A este propósito, Eduardo Lourenço refere-se a Portugal como possuidor de uma hiperidentidade, decorrente de um défice de identidade real, que compensa no plano imaginário (Silva \& Jorge, 1993). Esta é uma ideia próxima à de Boaventura de Sousa Santos (1990), que constata um excesso mítico de interpretação, num mecanismo para compensar o défice de realidade do país. José Gil é mais cáustico, referindo-se à "subjetividade produzida pela doença da identidade", e defende que a identidade portuguesa vive entre a realidade e a ficção (Gil, 2009: 10).

\section{Lusofonia e 'portugalidade'}

Uma das constatações que se podem fazer quando existem referências à lusofonia é a alusão a uma alegada centralidade portuguesa, numa tendência que, não raras vezes, passa por invocar uma alegada 'portugalidade'. Moisés de Lemos Martins refere-se ao discurso mítico como sendo pontuado pela ideologia, "o que permite dizer que os mitos têm um carácter político e que são 'estados de poder', ou seja, relações de dominação e de discriminação reificadas" (Martins, 2006b: 85; 2004: 94). Nesse sentido, os mitos refletem a voz do poder, com o seu acentuado grau de estereotipia a manifestar-se, por exemplo, "no carácter doxológico e celebrativo que apresentam" (ibid.). Nessa perspetiva os mitos pretendem persuadir, sendo essa a sua natureza retórica, dividindo a realidade e chamando à existência aquilo que enunciam (Martins, 2006b, 2004). O que quer dizer que "os enunciados míticos propõem-se como enunciados com autoridade, como enunciados que legitimam um discurso, policiando-o todavia" (Martins, 2006b: 85; 2004: 95).

Ora, esta perspetiva tanto é aplicável à 'portugalidade' como à lusofonia. Ambos os termos são hiperidentitários, não obstante o primeiro ter sido cunhado, como vimos, em pleno Estado Novo. 

Colocando de lado a ideia de que na lusofonia esteja apenas a "voz de quem manda, a reinar sozinha por cima da cabeça dos países de expressão portuguesa" (Martins, 2006b: 85-86; 2004: 95), é seu entendimento que ela valoriza antes os contributos africanos, ameríndios, orientais e europeus para uma civilização comum. É o domínio cultural que "deve sobrepor-se a questões de soberania, podendo florescer no seio de uma entidade transnacional ou nacional uma federação cultural com lugar para muitos Estados" (ibid., 86; ibid.: 95). Num contexto pós-colonial, "a figura da lusofonia convoca hoje uma comunidade transnacional, com propósitos político-culturais" (ibid.), exprimindo-se em multiculturalismos com o denominador comum de uma mesma língua.

ação da "portugalidade à lusofonia está bem patente no discurso político, nomeadamente no discurso dos deputados da Assembleia da República (AR) e de alguns governantes quando se deslocam ao hemiciclo. Muito embora de forma residual, todos eles associam ambos os conceitos. Em 1993, o ministro da Presidência, Fernando Nogueira, evidenciava as "ligações privilegiadas com outras zonas do mundo onde Portugal, por virtude da sua história, tem particular peso", a par das comunidades portuguesas espalhadas pelo mundo, "como referências de 'portugalidade' e da lusofonia" ${ }^{6}$. Dois anos mais tarde, já como deputado do PSD, o mesmo responsável político frisava que "a europeização de Portugal é condição para que continuemos a ter uma posição relevante no mundo da lusofonia e da portugalidade"'. Em 1996, Cruz Abecassis, deputado do CDS/PP, ligava a diáspora à 'portugalidade', durante a discussão de um projeto de resolução, apresentado pelo seu grupo parlamentar sobre a constituição de uma comissão eventual destinada a promover o projeto de uma comunidade de países de língua portuguesa (o que viria a ser a CPLP). Propunha a inserção de uma "enorme capacidade cultural, humana e até económica, que é a portugalidade na diáspora, com todas as suas empresas, toda a sua capacidade cultural e intelectual e toda a sua riqueza humana", com toda a sua vontade de ligação a este "esforço comum de desenvolvimento de uma parte importante e ignorada do mundo, que é África" ${ }^{8}$. Em 2007, na X Legislatura, a propósito da conquista por Naide Gomes da medalha de ouro em salto em comprimento nos Campeonatos Europeus de Atletismo em Pista Coberta, em Birmingham, a secretária da AR, Celeste Correia (PS), lia um voto de congratulação em que se afirmava que "no desporto e na representação internacional, mora a alma de um povo, sendo gratificante ver a portugalidade apreciada no contexto das nações e a convergir para uma dimensão humanista superior"; destacava-se ainda o "júbilo, orgulho e auto-estima que [a atleta] proporcion[ou] à comunidade e a todos os quadrantes da lusofonia"9.

outro plano, na abertura de um colóquio com o título genérico "Portugalidade e Lusofonia" ${ }^{10}$, Renato Epifânio, presidente do Movimento Internacional Lusófono (MIL), defendia que 'portugalidade' e lusofonia não são conceitos sinónimos mas, "de alguma forma [...] cumulativos". O autor associou a essa ideia todo o trabalho que o MIL tinha feito, "procurando defender esta convergência lusófona, nos planos cultural, social, económico e político e, mais do que isso, defender neste sentido, uma consciência e uma fraternidade lusófonas" (ibid.).

Ora, segundo Eduardo Lourenço, "aquilo que permitiria atribuir a verdadeira realidade e sentido à tão evocada lusofonia, não pode, nem sequer metaforicamente, ser pensado e imaginado como espaço de portugalidade" (Lourenço, 2004 [1999]: 186). A ideia de reunir num corpo "quase místico" a dispersa e diversificada "realidade histórico-cultural de conotação lusófona" deve deixar de lado o recorte centralista, "historicamente 
unificador" e que "era seu enquanto a nossa missão no mundo se resumia, primeiro, como expansão de Portugal e, depois, como decantada criação de novos Portugais" (ibid.: 188). Muito embora forjada em equívocos, Lourenço afirma que, dessa forma, "a assimilação de lusofonia e portugalidade podia ter então algum sentido", apesar de o autor sublinhar que "o espaço da lusofonia, não tanto o seu óbvio sentido linguístico, mas como espaço cultural, é um espaço se não explodido, pelo menos multipolar, intrinsecamente descentrado" (ibid.: 188). E querer uni-lo pode afigurar-se paradoxal e assente numa lógica eurocentrada; mais a mais, "quando nós fomos os primeiros agentes, inconscientes embora, da descentração europeia, é a melhor maneira de cortar pela raiz o sonho de comunhão, de expansão de nós mesmos como cultura que se quer vincular à ideiaprograma, agora ideológica, da lusofonia" (ibid.: 188-189).

Michel Cahen diz preferir a expressão "lusotopia" à de "lusofonia" para designar o conjunto de espaços e comunidades, quaisquer que tivessem sido a sua língua do passado e atual, mais ou menos forjadas ou constituídas pela história da expansão portuguesa. Ao contrário do que defendem, por exemplo, Moisés de Lemos Martins e Eduardo Lourenço, Michel Cahen afirma que a lusofonia não representa uma área cultural, mas um espaço pós-colonial específico, que apelida de "espaço 'relativo" (Cahen, 2013: 309), o que significa que existem culturas nas lusofonias, "mas [que] não constituem um plano global da comunidade cultural lusófona, a não ser que se reduza à área luso-brasileira" (ibid.). Trata-se de uma ideia que pode ser aplicada à hispanofonia, francofonia ou à anglofonia, embora, no caso português, Cahen observe que "o imaginário foi aguçado pelo sentimento de fraqueza da antiga metrópole", sendo por isso "incapaz de se constituir uma 'pré-base' neocolonial do tipo francês" (ibid.: 309). Essa "identidade superficial" da lusofonia, que Michel Cahen apelida de "supra-identidade" e que é reforçada pela mercantilização da língua, é levada adiante pelas pessoas implicadas, "quando lhes interessa, como no caso dos brasileiros ou cabo-verdianos, que imigram para Portugal" (ibid.: 309-310). 0 autor destaca, porém, que a ideia de "identidade superfi cial", que é a lusofonia, "é típica de situações fluidas que alguns qualificam de pós-modernas", não podendo ser 'reificada' numa comunidade humana unificada" (ibid.: 310).

\section{Equívocos da lusofonia}

Colocando em perspetiva as várias ideias existentes sobre a lusofonia, Moisés de Lemos Martins encara-a à luz de alguns equívocos, muito embora faça o mapeamento do campo que lhe deu origem, mormente no que respeita à compreensão do mundo por parte do Ocidente. Para este sociólogo, o Ocidente foi feito sob a égide da cultura da unidade, numa definição 'clássica' assente na existência da totalidade de um caminho - incluindo um princípio, um meio e um fim (que pressupunha um Deus criador) (Martins, 2011: 17-21). Os Descobrimentos são uma prova disso mesmo. Mais tarde, no século XIX, na sequência do Tratado de Berlim determina-se que o direito histórico, por si só, não é sufi ciente, pelo que os países com 'colónias' tinham de ocupar os territórios através da 'lei do mais forte'. Na sequência do ultimato inglês, os portugueses deram início às campanhas militares em África, assumindo o papel de agressores. Assim, segundo Moisés de Lemos Martins, à cultura do uno, "logocêntrica, etnocêntrica e imperialista, que assimilava a diferença, destruindo-a", sucedeu "a cultura do múltiplo e da participação, a da multiculturalidade" (Martins, 2014: 21). Esta cultura do múltiplo e da participação exprime-se "no surgimento de uma vasta panóplia de países diferentes e multiculturais, fundados na riqueza de 
muitas línguas, na mistura de muitas etnias e na explosão de uma multiplicidade de narrativas" (ibid.: 21-22). Só que esse recorte de uma cultura multifacetada, com a instantaneidade da globalização, decorrente do esbatimento progressivo dos padrões circulares de reprodução temporal, foi 'sol de pouca dura', porque hoje, como assinala o autor, "por todo o lado, a cultura do uno voltou a levar a melhor sobre a diferença, e a multiculturalidade regride em favor da "cultura-mundo"'; trata-se, portanto, de uma ideia "homogeneizante e empobrecedora das culturas, que dilui memórias e fronteiras, virtualiza paisagens e apaga povos e nações" (ibid.: 22). "É este o contexto em que se insere a lusofonia como movimento multicultural de povos que falam a mesma língua, o português" (ibid:: 25) ${ }^{11}$ : Ao invés da "homogeneização empobrecedora e de sentido único, estabelecida pela globalização cosmopolita, [a lusofonia] tem a virtude do heterogéneo; a sedução de uma rede [...] capaz de resistir à redução do diverso a uma unidade artificial" ( ibid.).

Esta oportunidade é fustigada, todavia, por alguns aspetos que podem colocar em causa essa diversidade. Por essa razão, Moisés de Lemos Martins enumera quatro equívocos que diz ser necessário desconstruir: i) o equívoco da centralidade portuguesa ['portugalidade'], em 'que ressoa, embora remotamente, ainda uma 'visão lusocêntrica' salazarista (ibid.: 25); ii) o equívoco da reconstrução de narrativas do antigo império em contexto pós-colonial (hoje com propósitos neocoloniais, sejam eles conscientes ou inconscientes), referindo que, "nos casos de países africanos multilingues, como Angola e Moçambique, a lusofonia pode não passar de 'lusoafonias' (numa referência direta a um texto homónimo de Mia Couto" (ibid.: 26); iii) o equívoco do luso-tropicalismo e da ideia de colonização doce, "renascente e redivivo", que hoje "tanto pode glorificar o antigo país colonial como exaltar os atuais países independentes" (ibid.); finalmente, iv) o equívoco da "narrativa de uma história do ressentimento", resultante de algum discurso pós-colonial, "um discurso que se constitui como uma espécie de vindicta histórica, de 'révanche' serôdia, a pretexto de resgatar a memória de um passado colonial" (ibid.: 26-27). A este propósito, Moisés de Lemos Martins convoca Harold Bloom, que se refere, nesse âmbito, à "Escola do ressentimento", associando "afrocentristas a feministas, marxistas, novoshistoricistas de inspiração foucaultiana, ou desconstrutores", numa crítica que considera "controversa", enaltecendo "aquilo que designa como Cânone Ocidental", mas desqualificando "como 'ressentidos' aqueles a que chama de 'multiculturalistas"' (ibid.: 26).

\section{Notas finais}

31 Depois de cruzadas algumas das diferentes perspetivas relativas à lusofonia, torna-se claro que a ideia que a sustenta não é pacífica. $O$ termo, nos tempos que correm, assume um recorte pós-colonial, cuja palavra-chave é "interculturalidade", pelo que implicará, desde logo, a desmontagem de eventuais clivagens entre ex-colonizadores e excolonizados, uma vez que pressupõe um mesmo plano para todos os atores intervenientes.

Marcada pela crescente globalização, a realidade pós-colonial integra as diferentes identidades locais, bem como as diferentes formas que elas assumem. João Maria André declara que o multiculturalismo constitui uma temática "incontornável", repercutindo-se nas sociedades em que "todos somos, de algum modo, mestiços e, por isso, todos tendemos, no futuro, a navegar nos labirintos das nossas mestiçagens" (André, 2002: 276). 
Não obstante, o conceito está "prenhe de equívocos", como refere Inocência Mata, que sublinha no entanto concordar com a sua emergência "enquanto estratégia que responde à exigência de reconhecimento das identidades culturais minoritárias sem configuração regional no conjunto nacional, mas que reivindicam o estatuto de pertença ao corpo nacional" (Mata, 2007: 291). E, mais do que ao multiculturalismo, a referência à "interculturalidade" deve ser efetiva, mesmo que se tenha de perceber que o mundo mais pequeno que a globalização fornece não é diretamente proporcional a "formas diferentes de enunciar desigualdades" (Cabecinhas \& Cunha, 2008: 7). Para além disso existe ainda o risco de se poder "confundir diálogo com simetria e interculturalidade com igualdade das partes" (ibid.: 8), sendo que o tão em voga diálogo com o 'outro' quase se resume a uma dimensão folclórica, mesmo que a abertura ao 'outro' signifique “transformação recíproca" (ibid.: 9).

Dessa forma, a palavra ou, numa dimensão mais ampla, a ideia de 'portugalidade' é incompatível com o conceito de lusofonia, já que remete para uma centralidade portuguesa, independentemente do sentido que lhe é dado, como que 'adaptando-o' a cada momento da história, o que não é compaginável com uma lógica pós-colonial. Esta ideia foi, de resto, sublinhada por Moisés de Lemos Martins no texto "A lusofonia como promessa e o seu equívoco lusocêntrico" (Martins, 2006b: 79-87) ou por Stuart Hall (2000), a propósito da 'britishness' (britanidade), a qual diz tratar-se de uma espécie de racismo cultural.

Como defende Maria Manuel Baptista, é necessário "re-imaginar a lusofonia" e "descolonizar o pensamento", o que consiste numa tarefa que passa "pela procura de um pensamento estratégico que inclua uma refl exão colonialista/pós-colonialista/ descolonialista" (Baptista, 2013: s/p). Para tanto, é necessário trabalhar "as relações entre países, entre comunidades recetoras e emigrantes, entre o norte e o sul, entre o mundo anglófono e o outro, entre o saber erudito e o saber comum, o saber sobre o homem e o conhecimento técnico" (ibid.), no sentido de se colocar em causa a hegemonia ocidental, numa tarefa que deve ser o mais abrangente possível.

\section{BIBLIOGRAFIA}

ALMEIDA, Onésimo Teotónio (2008), “A propósito de lusofonia (à falta de outro termo): o que a língua não é”, Blogue História Lusófona (2008/05/07) [Online], disponível em http:// tinyurl.com/6tyl3uc [Consultado em: 5/2/2010].

BAPTISTA, Maria Manuel (2013), "Re-imaginar a Lusofonia ou da necessidade de descolonizar o conhecimento", IV Congresso Internacional em Estudos Culturais (Colonialismos, Póscolonialismos e Lusofonias), Aveiro, 28-30 de abril, 2014 [Online], disponível em http://tinyurl.com/mqsuauq [Consultado em: 6/1/2013].

BAPTISTA, Maria Manuel (2006), “A Lusofonia não é um jardim. Ou da necessidade de "perder o medo’ às realidades e aos mosquitos”, in MARTINS, M. L.; SOUSA, H. \& CABECINHAS, R. (eds.), Comunicação e Lusofonia - Para uma abordagem crítica da cultura e dos media. Porto: Campo das Letras, 15-18. 
BAPTISTA, Maria Manuel (2000), “O conceito de Lusofonia em Eduardo Lourenço: Para além do multiculturalismo pós-humanista”, III Seminário Internacional "Lusografias”, Évora, 8-11 de novembro, 2000 [Online], disponível em http://tinyurl.com/cecls78 [Consultado em: 3/3/2012].

BARTHES, Roland (1978 [1957]), Mitologias. Lisboa: Edições 70.

BRITO, Regina \& BASTOS, Neusa (2006), “Dimensão semântica e perspectiva do real: comentários em torno do conceito de lusofonia", in MARTINS, M. L.; SOUSA, H. \& CABECINHAS, R. (eds.), Comunicação e Lusofonia - Para uma abordagem crítica da cultura e dos media. Porto: Campo das Letras, 65-77.

BRITO, Regina \& MARTINS, Moisés (2004), "Moçambique e Timor-Leste: onde também se fala o português", III Congresso da Sopcom, UBI, CECS. [Online], disponível em http:// hdl.handle.net/1822/1005 [Consultado em: 20/12/2013].

CABECINHAS, Rosa \& CUNHA, Luís (2008), "Introdução. Da importância do diálogo ao desafio da interculturalidade”, in CABECINHAS, Rosa \& CUNHA, Luís (eds.), Comunicação Intercultural. Perspectivas, dilemas e desafi os. Porto: Campo das Letras, 7-12.

CAHEN, Michel (2013), "Portugal is in the Sky': Conceptual considerations on communities, lusitanity, and lusophony”, in MORIER-GENOUD, Eric \& CAHEN, Michel, Imperial Migrations. Colonial Communities and Diaspora in the Portuguese World. Houndmills, Basingstoke, Hampshire/ Nova Iorque: Palgrave Macmillan, 297-315.

CASTELEIRO, José Malaca (coord.) (2001), Dicionário da Língua Portuguesa Contemporânea. Lisboa: Academia das Ciências de Lisboa/Verbo.

COSTA, Almeida \& MELO, Sampaio (1995), Dicionário da Língua Portuguesa. Porto: Porto Editora.

CUCHE, Denys (2006 [1999]), A Noção de Cultura nas Ciências Sociais. Lisboa: Fim de Século.

FALCONI, Jessica (2013), “Literaturas africanas, língua portuguesa e narrativas da Lusofonia: Alguns parágrafos em torno da invenção das narrativas da 'Lusofonia”, in LEITE, A. M.; OWEN, H.; CHAVES, R. \& APA, L., Nação e Narrativa Pós-Colonial - 1. Angola e Moçambique. Ensaios. Lisboa: Edições Colibri, 277-289.

FRANCO, José Eduardo (s/d), “Mitos da construção da identidade nacional e emocional: uma perspectiva comparativa luso-polaca (parte II)", in CALAFATE, Pedro; FRANCO, José Eduardo \& CIESZYNSKA, Beata, Mitos da Construção da Identidade Nacional e Emocional: Uma perspectiva comparativa luso-polaca, [Online], disponível em [http://tinyurl.com/27gxkkm [Consultado em: 6/11/2010].

FREIRE, Rita Silva (2012), "Dar ancas às consoantes e devolver seios às vogais”, Sol (18/10/2012) [Online], disponível em http://tinyurl.com/olswoay [Consultado em: 28/10/2012].

GIL, José (2009), Em Busca da Identidade - O desnorte. Lisboa: Relógio d'Água.

GONÇALVES, Albertino (2009), 'O ceptro e a máscara. Discursos de identidade, reificação e poder', in GONÇALVES, Albertino (org.), Vertigens. Para uma sociologia da perversidade. Coimbra: Grácio Editor/CECS-UMinho, 61-63.

HALL, Stuart (2000), A Identidade Cultural na Pós-modernidade, Rio de Janeiro: DP\&A.

HOUAISS Antônio \& VILLAR, Mauro de Salles (2003 [2011]), Dicionário Houaiss da Língua Portuguesa. Lisboa: Círculo de Leitores.

LOURENÇO, Eduardo (2005), A Morte de Colombo. Metamorfose e fim do Ocidente como mito. Lisboa: Gradiva. 
LOURENÇO, Eduardo (2004 [1999]), A Nau de Ícaro seguido de Imagem e Miragem da Lusofonia. Lisboa: Gradiva.

LOURENÇO, Eduardo (1954), "Situação do existencialismo”, Revista Filosófica, Coimbra, n. 10, maio: $62-70$.

MACIEL, Carmen (2000), A Construção da Comunidade Lusófona a partir do Antigo Centro: Microcomunidades e práticas da lusofonia, Dissertação de Doutoramento em Sociologia, Lisboa: Faculdade de Ciências Sociais e Humanas/Universidade Nova de Lisboa.

MADEIRA, Ana Isabel (2003), Sons e Silêncios da Lusofonia: Uma reflexão sobre os espaços-tempos da língua portuguesa. Lisboa: EDUCA.

MARGARIDO, Alfredo (2000), A Lusofonia e os Lusófonos: Novos mitos portugueses. Lisboa: Edições Universitárias Lusófonas.

MARTINS, Leonor Pires (2012), Um Império de Papel. Lisboa: Edições 70.

MARTINS, Moisés de Lemos (2014), "Língua portuguesa, globalização e lusofonia", in BASTOS, Neusa (org.), Língua Portuguesa e Lusofonia. São Paulo: EDUC - IP-PUC, 15-33.

MARTINS, Moisés de Lemos (2011), Crise no Castelo da Cultura. Coimbra: Grácio Editor/ CECSUMinho.

MARTINS, Moisés de Lemos (2006a), “Continente imaterial”, in MARTINS, Moisés de Lemos; SOUSA, Helena \& CABECINHAS, Rosa (eds.), Comunicação e Lusofonia - Para uma abordagem crítica da cultura e dos media. Porto: Campo das Letras, 15-18.

MARTINS, Moisés de Lemos (2006b), "A lusofonia como promessa e o seu equívoco lusocêntrico", in MARTINS, Moisés de Lemos; SOUSA, Helena \& CABECINHAS, Rosa (eds.), Comunicação e Lusofonia - Para uma abordagem crítica da cultura e dos media. Porto: Campo das Letras, 79-87.

MARTINS, Moisés de Lemos (2004), "Lusofonia e Luso-tropicalismo. Equívocos e possibilidades de dois conceitos hiper-identitários", Visages d'Amérique Latine, n. 3 - Juin 2006, pp. 89-96, [Online], disponível em: http://tinyurl.com/k9yodpg [consultado em: 12/12/2013].

MARTINS, Moisés de Lemos (1996), Para uma Inversa Navegação. O discurso da identidade. Porto: Afrontamento.

MARTINS, Moisés de Lemos; SOUSA, Helena \& CABECINHAS, Rosa (2007), "Lusocom: Estudos das políticas de comunicação e discursos no espaço lusófono”, in LEDO ANDIÓN, Margarita (ed.) (2007), Comunicación local no espazo lusófono. Santiago de Compostela: Associación Galega de Investigadores/as en Comunicación, 301-310.

MATA, Inocência (2013), “A Invenção do espaço lusófono: a lógica da razão africana”, in CRISTÓVÃO, Fernando (coord.), Ensaios Lusófonos. Coimbra: Almedina, 141-153.

MENESES, Maria Paula (2013), "Nação e narrativas pós-coloniais: interrogações em torno dos processos identitários em Moçambique”, in LEITE, Ana Mafalda; OWEN, Hilary; CHAVES, Rita \& APA, Livia (orgs.), Nação e Narrativa Pós-Colonial I. Lisboa: Edições Colibri, 311-322.

REAL, Miguel (2012), A Vocação Histórica de Portugal. Lisboa: Esfera do Caos Editores.

RICHARDS, Thomas (1993), The Imperial Archive. Knowledge and the Fantasy of Empire. London/ New York: Verso.

ROSAS, Fernando (2001), "O Salazarismo e o Homem Novo: Ensaio sobre o Estado Novo e a questão do totalitarismo”, Análise Social, vol. XXXV (157), Lisboa: ICS, 1031-1054.

SAID, Edward (1994), Culture and Imperialism. London: Vintage. 
SANCHES, Margarida Ribeiro (2012), “A bem da Europa e das suas nações”, in MARTINS, Leonor Pires (org.), Um Império de Papel. Lisboa: Edições 70, 195-207.

SANCHES, Margarida Ribeiro (2011) "Viagens da teoria antes do pós-colonial”, in SANCHES, Margarida Ribeiro (org.), Malhas que os Impérios Tecem. Textos anticoloniais, contextos pós-coloniais. Lisboa: Edições 70, 9-43.

SANTOS, Boaventura de Sousa (1999), “O Oriente: entre diferenças e desencontros”, Notícias do Milénio ("Diário de Notícias", 8-7-1999), 44-51.

SANTOS, Boaventura de Sousa (1990), Estado e Sociedade em Portugal (1974-1988). Porto: Afrontamento.

SILVA, Augusto Santos \& JORGE, Victor Oliveira (orgs.) (1993), Existe uma Cultura Portuguesa?, Colecção "História \& Ideias", n.. 6 (texto de mesa-redonda com várias personalidades, entre as quais Eduardo Lourenço, na Casa das Artes, no Porto, em 27/04/1992). Porto: Afrontamento.

SOUSA, Vítor (2013), “Fantasia Lusitana, de João Canijo: O Portugal fi ccional vs. o país real. o Estado Novo e a 'portugalidade'. A construção da identidade", in VALENTE, António Costa \& CAPUCHO, Rita, Avanca Cinema 2013 International Conference. Avanca: Edições Cine-Clube de Avanca, 623-630.

TORGAL, Luís Reis (2009), Estados Novos, Estado Novo, vol. 1. Coimbra: Imprensa da Universidade de Coimbra.

VENÂNCIO, José Carlos (2013), "Lusofonia e cânone lusófono. Da controvérsia dos conceitos à manifestação de duas escritas a partir da margem”, in CRISTÓVÃO, Fernando (org.), Ensaios Lusófonos. Coimbra, Almedina, 83-99.

WITTGENSTEIN, Ludwig (1958), The Blue and Brown Books. Oxford: Blackwell.

\section{NOTAS}

1. A lusofonia é, normalmente, traduzida pelos dicionários como o conjunto de identidades culturais existentes em países, regiões, Estados ou cidades falantes da língua portuguesa, como são os casos de Angola, Brasil, Cabo Verde, Guiné-Bissau, Macau, Moçambique, Portugal, São Tomé e Príncipe, Timor- Leste, bem como por outras comunidades em todo o mundo, como os antigos territórios portugueses da Índia, China e Malásia. Ana Isabel Madeira refere que a lusofonia comporta ainda o português da Galiza (Madeira, 2003: 12). Ver também Brito e Martins (2004: 3): “[é]num contexto geograficamente disperso, naturalmente multicultural, de sistemas linguísticos vários e de diferentes normas do português, que é possível pensar a língua e a identidade lusófonas."

2. O documento pode ser lido e descarregado na íntegra na página ofi cial da CPLP [informação disponível em http://tinyurl.com/mwpnlc5, acedida em 28/01/2013].

3. Bom, J. C. (2000), 'Portugalidade, pergunta-resposta', in Ciberdúvidas da Língua Portuguesa, de 7/4/2000 [informação disponível em http://tinyurl.com/2uanuhv, acedida em novembro de 2010].

4. Duarte, C. (2005), "Portuguesismo, portugalismo, portugalidade, pergunta-resposta", in Ciberdúvidas da Língua Portuguesa, de 14/2/2005 [informação disponível em http:// tinyurl.com/2ueratv, acedida em novembro de 2010].

5. "Se tivéssemos de nomear a vida do signo, teríamos de dizer que a vida do signo é o seu uso" (Wittgenstein, 1958: 4).

6. VI Legislatura, sessão 2, n.ำ 80, de 04-06-1993, diário de 05-06-1993, p. 2552. 
7. VII Legislatura, sessão 1, n.ำ 15, de 13-12-1995, diário de 14-12-1995, p. 425.

8. VII Legislatura, sessão 1, n.ำ 23, de 05-01-1996, diário de 06-01-1996, p. 657.

9. X Legislatura, sessão 2, n. 58, de 08-03-2007, diário de 09-03-2007, p. 37.

10. O Colóquio "Portugalidade e Lusofonia" realizou-se em 27 de novembro de 2013, no Palácio da Independência (Lisboa), tendo sido organizado pela Comissão do $1 .^{\circ}$ de Dezembro de 1640 da Sociedade Histórica da Independência de Portugal e pelo Movimento Internacional Lusófono/ Revista Nova Águia, com coordenação de Lourenço d'Almada e Renato Epifânio. Teve intervenções de Pedro Martins ("Portugalidade e Lusofonia: entre Camões e António Telmo"), Miguel Real ("Portugalidade e Lusofonia: entre António Vieira e Fernando Pessoa"), Rodrigo Sobral Cunha ("Portugalidade e Lusofonia: entre Pascoaes e António Quadros) e Renato Epifânio ("Portugalidade e Lusofonia: entre Leonardo Coimbra e Agostinho da Silva" [informação disponível em http://tinyurl.com/p3h8e8y, acedida em 28/11/2013].

11. A este propósito, no III Encontro de Escritores em Natal (Brasil), Mia Couto referia que, "mais do que me inspirar na tradição oral, a minha intenção é introduzir os universos da oralidade na lógica da escrita, devolver à palavra grafada o gesto, o corpo, o sexo da fala", acrescentando ser isso que o anima enquanto escritor: "ensinar a minha escrita a dançar, dar ancas às consoantes, devolver seios às vogais e, enfim, reinventar sensualidades que foram sendo roubadas pela cega obediência às normas da gramática" (Freire, R. S., 2012: s/p). Já antes, Onésimo Teotónio Almeida tinha observado que "os brasileiros desengravataram o português" e "os americanos arregaçaram as mangas ao inglês e vestiram-lhe jeans" (Almeida, 2008: s/p).

\section{RESUMOS}

Com este artigo, pretendemos observar de que modo a 'portugalidade' - termo cunhado durante o Estado Novo - pontua a construção da lusofonia, que é um conceito pós-colonial. Não obstante afirmar-se que apenas falta colocá-lo em prática, o conceito de lusofonia não é consensual, subsistindo vários equívocos interpretativos. Ou se olha para ele a partir de uma centralidade portuguesa, reconstruindo as narrativas do antigo império, pela via do luso-tropicalismo ou ainda numa lógica de história do ressentimento. Ainda que, de forma residual, o discurso político português faça a ligação entre 'portugalidade' e lusofonia, concluímos que ambos os conceitos, quando associados, são incompatíveis, já que remetem sempre para uma centralidade portuguesa, o que não é compaginável com uma lógica pós-colonial, de interculturalidade.

In this article we set out to show how 'Portugality', a term coined under the Estado Novo (New State) regime, peppers the construction of lusophony, which is a postcolonial concept. Though it is said that all that remains is to put it into practice, the concept of lusophony is not consensual since it has been interpreted in various ways. It is viewed from the standpoint of Portuguese centrality, with the reconstruction of narratives from the former empire, or via lusotropicalism, or from the perspective of a history of resentment. Even though Portuguese political discourse forms the link between 'Portugality' and lusophony, albeit residually, we conclude that when associated the two concepts are incompatible. This is because they always refer to a Portuguese centrality that cannot be reconciled with a postcolonial rationale of interculturality.

Dans cet article, nous nous proposons de réfléchir comment la 'portugalité', un terme inventé pendant l'État Nouveau (Estado Novo), ponctue la construction de la lusophonie, qui est un 
concept postcolonial. Même si l'on dit qu'il ne manque plus que de le mettre en pratique, le concept de lusophonie n'est pas consensuel, puisqu'il subsiste diverses interprétations équivoques. Du point de vue portugais, la lusophonie est souvent considérée comme une reconstruction de récits de l'ancien empire, via le luso-tropicalisme, ou du point de vue de l'histoire du ressentiment. Même si le discours politique portugais fait le lien entre la 'portugalité' et la lusophonie, nous concluons que, lorsqu'elles sont associées, les deux notions sont incompatibles, parce qu'elles se réfèrent toujours à une centralité portugaise qui ne peut pas être conciliée avec une logique postcoloniale de l'interculturalité.

\section{ÍNDICE}

Mots-clés: lusophonie, empire, décolonisation, «portugalité»

Palavras-chave: lusofonia, império, descolonização, 'portugalidade'

Keywords: Lusophony, empire, decolonisation, 'portugality'

\section{AUTOR}

\section{VÍTOR DE SOUSA}

CECS-Centro de Estudos de Comunicação e Sociedade, Universidade do Minho vitordesousa@gmail.com 